\title{
Fabrication of AlGaN High Frequency Bulk Acoustic Resonator by Reactive RF Magnetron Co-sputtering System
}

\author{
Yu-Chen Chang ${ }^{1}$, Ying-Chung Chen ${ }^{1}$ and Chien-Chuan Cheng ${ }^{2, *}$ \\ 1 Department of Electrical Engineering, National Sun Yat-sen University, Kaohsiung 80424, Taiwan; \\ d043010004@student.nsysu.edu.tw (Y.-C.C.); ycc@mail.ee.nsysu.edu.tw (Y.-C.C.) \\ 2 Department of Electronic Engineering, HungKuo Delin University of Technology, New Taipei 236, Taiwan \\ * Correspondence: chengccc@mail.hdut.edu.tw
}

check for updates

Citation: Chang, Y.-C.; Chen, Y.-C.; Cheng, C.-C. Fabrication of AlGaN High Frequency Bulk Acoustic

Resonator by Reactive RF Magnetron Co-sputtering System. Materials 2021, 14, 7377. https://doi.org/10.3390/ ma14237377

Academic Editors: Silvia

Maria Deambrosis, Cecilia Mortalò and Valentina Zin

Received: 15 October 2021

Accepted: 23 November 2021

Published: 1 December 2021

Publisher's Note: MDPI stays neutral with regard to jurisdictional claims in published maps and institutional affiliations.

Copyright: (c) 2021 by the authors. Licensee MDPI, Basel, Switzerland. This article is an open access article distributed under the terms and conditions of the Creative Commons Attribution (CC BY) license (https:// creativecommons.org/licenses/by/ $4.0 /)$.

\begin{abstract}
In this study, aluminum gallium nitride (AlGaN) thin films are used as the piezoelectric layers to fabricate solidly mounted resonators (SMR) for high frequency acoustic wave devices. $\mathrm{AlGaN}$ film is deposited on a Bragg reflector, composed of three pairs of $\mathrm{Mo}$ and $\mathrm{SiO}_{2}$ films, through a reactive radio frequency $(\mathrm{RF})$ magnetron co-sputtering system at room temperature. The optimized deposition parameters of AlGaN film have a sputtering power of $175 \mathrm{~W}$ for $\mathrm{Al}$ target, sputtering power of $25 \mathrm{~W}$ for $\mathrm{GaN}$ target, $\mathrm{N}_{2}$ flow ratio $\left(\mathrm{N}_{2} / \mathrm{Ar}+\mathrm{N}_{2}\right)$ of $60 \%$, and sputtering pressure of 10 mTorr. The obtained AlGaN film has a smooth surface, uniform crystal grains, and strong c-axis orientation. The contents of $\mathrm{Al}$ and $\mathrm{Ga}$ in the $\mathrm{AlGaN}$ film, analyzed by energy dispersive X-ray spectroscopy (EDS) are $81 \%$ and $19 \%$, respectively. Finally, the frequency response $s_{11}$ of the obtained SMR device shows that the center frequency is $3.60 \mathrm{GHz}$, the return loss is about $-8.62 \mathrm{~dB}$, the electromechanical coupling coefficient $\left(\mathrm{k}_{\mathrm{t}}{ }^{2}\right)$ is $2.33 \%$, the quality factor $(\mathrm{Q})$ value is 96.93 and the figure of merit (FoM) value is 2.26 .
\end{abstract}

Keywords: piezoelectric; aluminum gallium nitride; solidly mounted resonator; frequency response

\section{Introduction}

In recent years, wireless communication systems have been advanced to $4 \mathrm{G}$ and $5 \mathrm{G}$. At the same time, the acoustic wave devices used in wireless communication equipment have higher requirements, such as frequency response, $\mathrm{k}_{\mathrm{t}}{ }^{2}, \mathrm{Q}$, and FoM [1-3]. The acoustic wave devices commonly used in wireless communication can be divided into bulk acoustic wave (BAW) and surface acoustic wave (SAW). The bulk acoustic wave device has lower insertion loss, higher frequency, and wider frequency band [4-8]; therefore, it is suitable for high frequency wireless communication system applications. The BAW resonator has two kinds of structure, one is the film bulk acoustic resonator (FBAR), and the other is solidly mounted resonator (SMR). The SMR structure does not require an etching process like the FBAR structure; therefore, it is relatively stable, and the process yield of the device can be improved [8-13].

On the other hand, the commonly used piezoelectric materials in acoustic wave devices are aluminum nitride ( $\mathrm{AlN})$ and zinc oxide $(\mathrm{ZnO})$ [14-17]. In recent years, some literature has studied the applications of $\mathrm{AlGaN}$ and $\mathrm{AlScN}$ in acoustic wave devices [18,19]. Both Wurtzite AlN and GaN have c-axis-oriented polarities and similar piezoelectric characteristics [20]. Therefore, GaN and AlGaN are also suitable for the applications of acoustic wave devices. In order to obtain high qualities of GaN and AlGaN, it often needs high temperature processes [21-23]. In 2016, J.B. Shealy et al. successfully fabricated thin film bulk acoustic resonators (FBAR) with single crystal AlGaN thin films, prepared using metal-organic chemical vapor deposition (MOCVD) method [18]. On the other hand, sputtering has lots of advantages such as low temperature growth, enhanced film quality with smaller grain size, and surface roughness, etc. In 2021, N.A. Othman et al. deposited $\mathrm{AlGaN}$ thin films on $\mathrm{Si}$ substrates through a co-sputtering technique. The structures 
and morphological characteristics of AlGaN films were discussed [24]. In this study, piezoelectric $\mathrm{AlGaN}$ thin films were deposited by a reactive RF magnetron co-sputtering system at room temperature to fabricate solidly mounted resonators (SMR) with a center frequency of around $3.5 \mathrm{GHz}$.

\section{Materials and Methods}

The structure of an SMR device, consisting of a Bragg reflector on a Si substrate, a bottom electrode, a piezoelectric layer, and a top electrode, is shown in Figure 1. The Bragg reflector was composed of 3 pairs of $\mathrm{Mo}$ and $\mathrm{SiO}_{2}$ films as high and low acoustic impedance layers, which were deposited using a direct current (DC) sputtering system and a reactive RF magnetron sputtering system, respectively. The thicknesses of Mo and $\mathrm{SiO}_{2}$ films were calculated to be $437 \mathrm{~nm}$ and $361 \mathrm{~nm}$ to fit the desired $3.5 \mathrm{GHz}$ frequency response of SMR devices, through the theoretical formula of $\mathrm{v}=\mathrm{f} \times 4 \mathrm{~d}$, in which, $\mathrm{v}$ and $4 \mathrm{~d}$ were the velocity and thickness of individual Mo or $\mathrm{SiO}_{2}$ film, respectively, and $\mathrm{f}$ was the center frequency of resonance. $\mathrm{Pt} / \mathrm{Ti}(100 \mathrm{~nm} / 12 \mathrm{~nm})$ thin films as the bottom and top electrodes were deposited on the Bragg reflector and piezoelectric layer by a DC sputtering system. The piezoelectric AlGaN thin film was deposited by a reactive RF magnetron co-sputtering system. A 2 inch metallic Al (99.999\% purity) and a 2 inch alloyed GaN (99.999\% purity) were used as the source targets. The RF sputtering power supplies were applied to $\mathrm{Al}$ and $\mathrm{GaN}$ targets, separately, and the sputtering pressure was varied from 10 mTorr to 30 mTorr with gas flow ratio $\left(\mathrm{N}_{2} / \mathrm{N}_{2}+\mathrm{Ar}\right)$ of $60 \%$, to deposit AlGaN thin films at room temperature. The preferred orientation and crystal characteristics of AlGaN films were analyzed by X-ray diffraction (XRD, Bruker D8 Advance) with CuK $\alpha$ radiation. The surface morphologies and cross-sectional images of the AlGaN films were analyzed by a scanning electron microscope (SEM, JEOL JSM-6700F). The element analysis of AlGaN film was carried out by energy dispersive X-ray spectroscopy (EDS, JEOL JSM-6700F). The frequency response of the SMR device was measured by a network analyzer, E5071C, and a CASCADE high-frequency probe station.

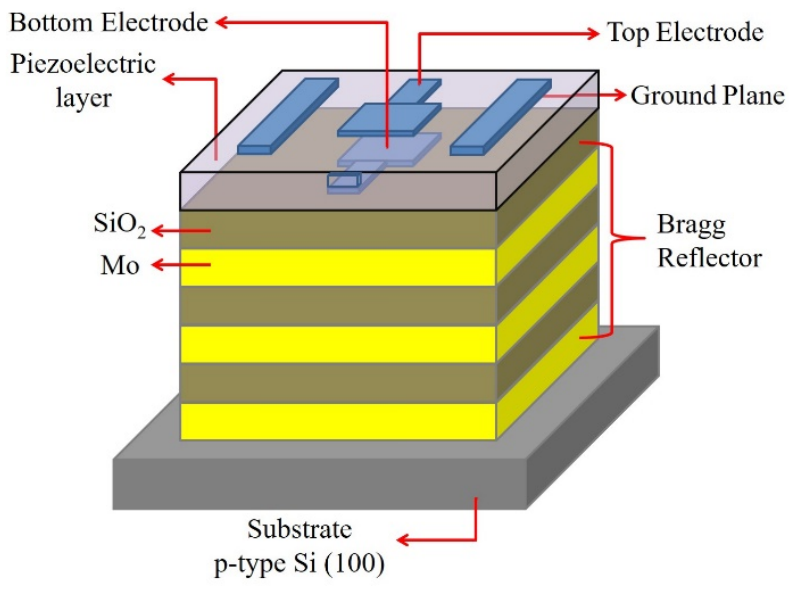

Figure 1. The structure of an SMR device.

\section{Results and Discussion}

In the study of $\mathrm{AlGaN}$ thin films, the deposition parameters of sputtering power, sputtering pressure, and gas flow ratio $\left(\mathrm{N}_{2} / \mathrm{N}_{2}+\mathrm{Ar}\right)$ were varied. The preliminary results showed that films exhibited better characteristics as the sputtering power of $175 \mathrm{~W}$ for $\mathrm{Al}$ target and $25 \mathrm{~W}$ for GaN target, respectively, and the gas flow ratio $\left(\mathrm{N}_{2} / \mathrm{N}_{2}+\mathrm{Ar}\right)$ of $60 \%$ at room temperature. This study was focused on the effects of sputtering pressure on the characteristics of AlGaN thin films. The sputtering pressure varied from 10 to $30 \mathrm{mTorr}$, and the crystalline structures, the surface morphologies, and the cross-sectional images of AlGaN thin films were discussed. 
The XRD patterns of the resulting AlGaN films deposited under different sputtering pressures are shown in Figure 2. It can be seen that the AlGaN films exhibit c-axis (002) orientation under sputtering pressures of $10 \mathrm{mTorr}$ and $20 \mathrm{mTorr}$. However, as the pressure increases further, the (002) peak intensity of the AlGaN film becomes weaker and even absent in the c-axis orientation. This phenomenon is similar to that reported by N.A. Othman et al. [24]; that is, the crystal quality of $\mathrm{AlGaN}$ film decreases as $\mathrm{N}_{2}$ flow increases.

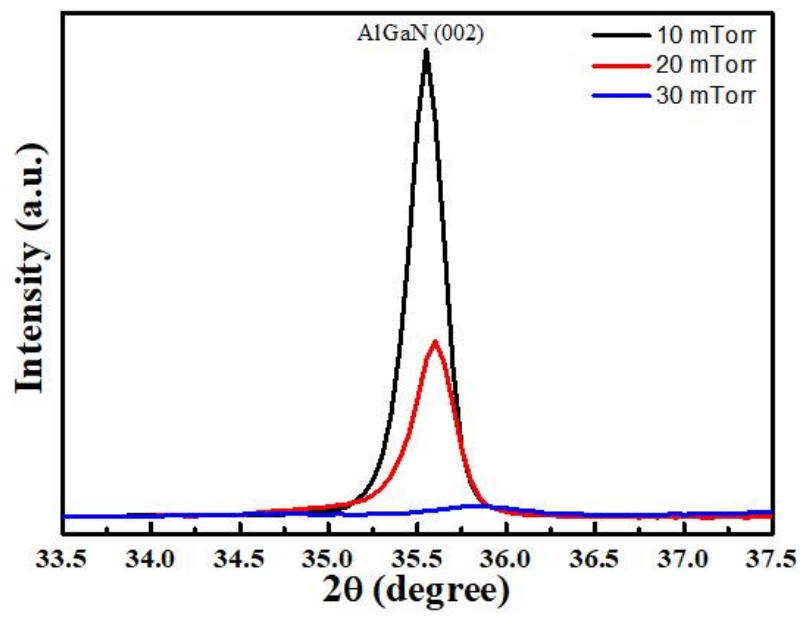

Figure 2. XRD patterns of the AlGaN films deposited under different sputtering pressures.

According to the literature, the diffraction peak of AlN (002) is about $2 \theta=36^{\circ}$ [17], while that of the $\mathrm{AlGaN}$ film deposited at sputtering pressure of 10 mTorr is about $2 \theta=35.55^{\circ}$. There exists a shift of $0.45^{\circ}$ for (002) diffraction peak between AlGaN and AlN films. The reason is that when gallium is doped into AlN, part of the larger Ga atoms replaces $\mathrm{Al}$ atoms in the lattice, which will result in the change of the lattice structure and cause the shift in the diffraction peak $[19,25]$. This phenomenon is similar to the doping of Sc atoms into AlN to form ScAlN films [26].

The surface morphologies and cross-sectional images of AlGaN thin films deposited under different sputtering pressures were analyzed by SEM, as shown in Figure 3. The films all present a uniform pebble-like surface morphology. However, it can be found from the cross-sectional images that when the sputtering pressure increases, the thickness of AlGaN film decreases from $1160 \mathrm{~nm}$ to $432 \mathrm{~nm}$ under a deposition time of $3 \mathrm{~h}$, and the film is unlikely to be deposited and there is no columnar structure. As the pressure increases, the structure of the $\mathrm{AlGaN}$ film gradually changes from the original pebble-like structure and columnar structure to an agglomerated structure. The overall crystal characteristics are also greatly degraded, which will have a large impact on the fabrication of SMR devices and may make the SMR devices have no frequency response. In order to obtain a $3.5 \mathrm{GHz}$ SMR resonator, three pairs of $\mathrm{Mo}$ and $\mathrm{SiO}_{2}$ films were deposited on a $\mathrm{Si}$ substrate as the Bragg reflector, on which bottom electrode ( $\mathrm{Pt} / \mathrm{Ti})$, piezoelectric $\mathrm{AlGaN}$ layer, and top electrode $(\mathrm{Pt} / \mathrm{Ti})$ were deposited in sequence. The cross-sectional image of an AlGaNbased SMR device is shown in Figure 4. The interfaces between the electrode layers, the piezoelectric layers, and the Bragg reflector layers are smooth, uniform, and clearly visible in the fabricated SMR device. The prepared piezoelectric AlGaN film has a columnar structure and c-axis orientation. The thickness of AlGaN film was adjusted to be about $770 \mathrm{~nm}$ by controlling the deposition time to fit the desired resonance frequency, according to the theoretical calculation of $\mathrm{v}=\mathrm{f} \times 2 \mathrm{~d}$-in which $\mathrm{v}$ was the wave velocity of AlGaN film, $\mathrm{f}$ was the center frequency, and $2 \mathrm{~d}$ was the thickness of AlGaN film. Besides, the element analysis of energy dispersive X-ray spectroscopy (EDS) showed that the contents of $\mathrm{Al}$ and $\mathrm{Ga}$ in the $\mathrm{AlGaN}$ film were $81 \%$ and $19 \%$, respectively. 


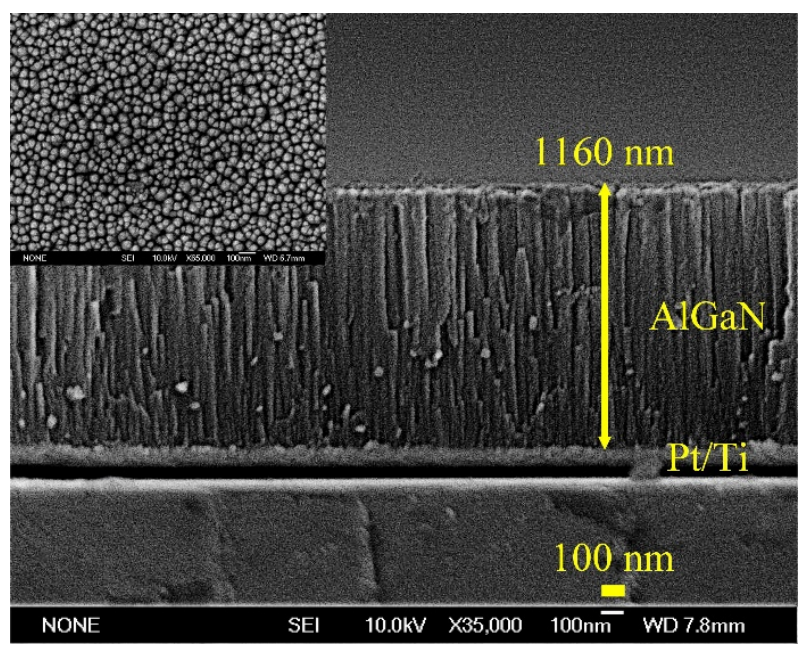

(a)

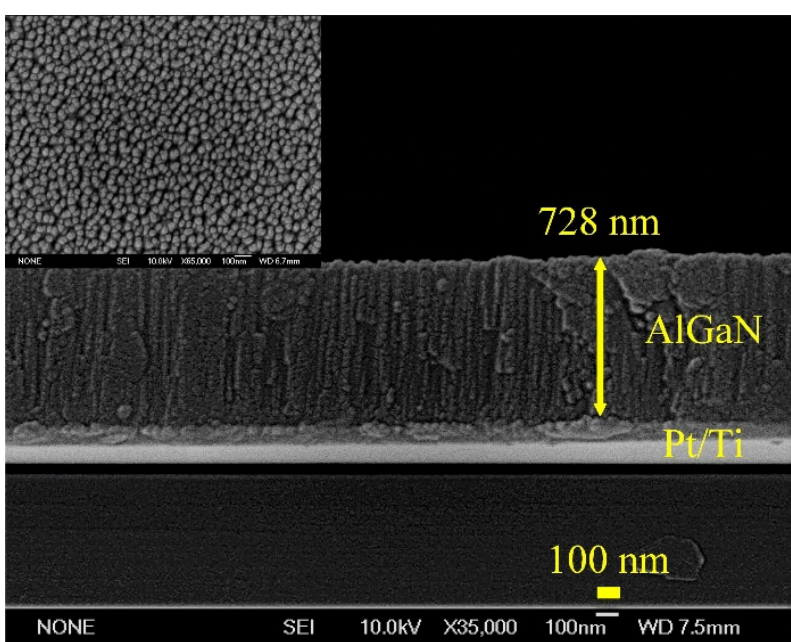

(b)

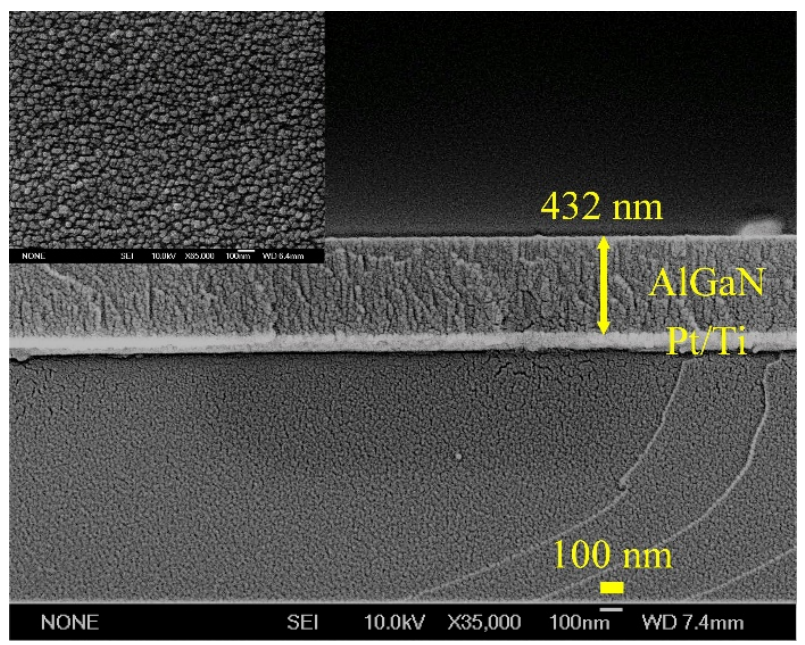

(c)

Figure 3. The surface morphologies and cross-sectional images of AlGaN films deposited under different sputtering pressures; (a) 10 mTorr, (b) 20 mTorr, and (c) 30 mTorr.

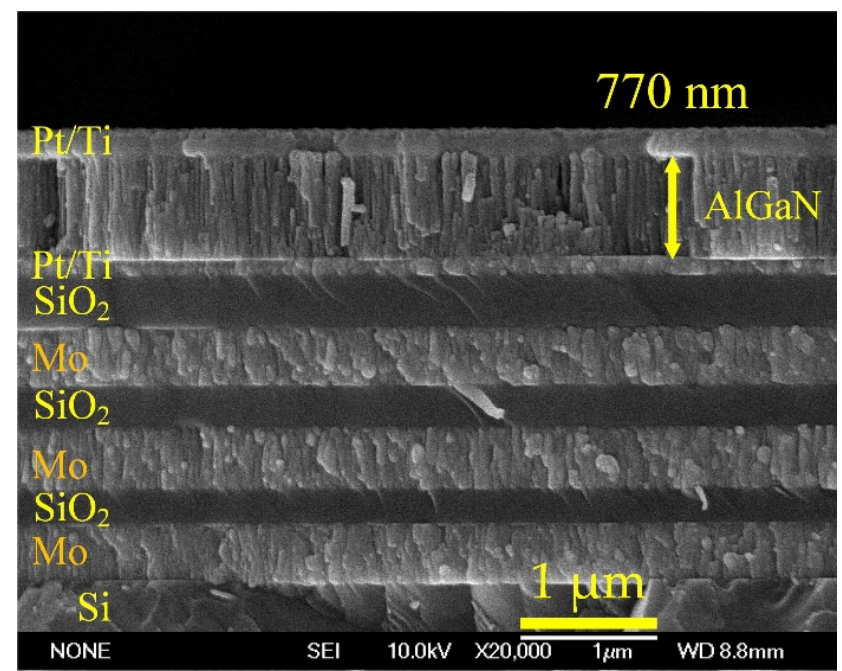

Figure 4. The cross-sectional image of an AlGaN-based SMR device.

The frequency response $\left(s_{11}\right)$ of the SMR device with $770 \mathrm{~nm}$ AlGaN film as the piezoelectric layer is shown in Figure 5. The results show that the resonance frequency and 
return loss of the SMR device are $3.6 \mathrm{GHz}$ and $-8.62 \mathrm{~dB}$, respectively.

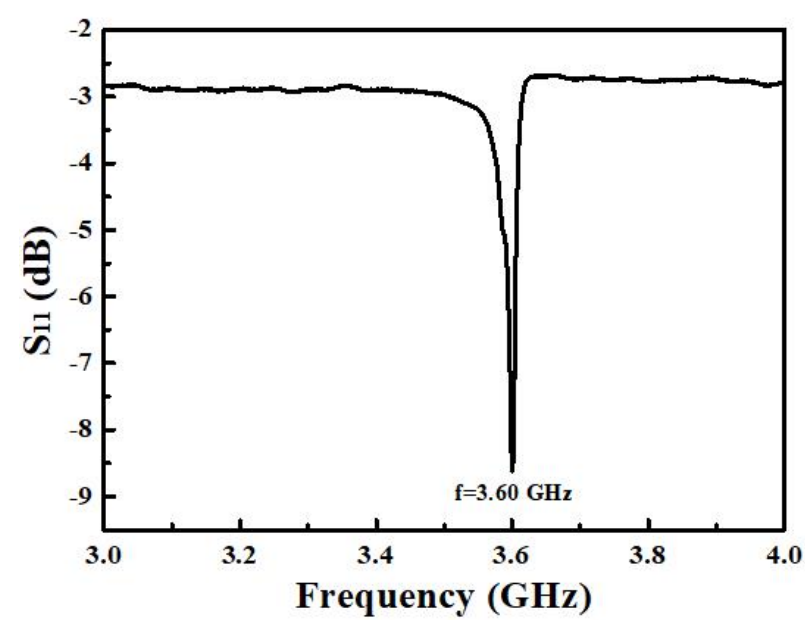

Figure 5. Frequency response of the SMR device with $770 \mathrm{~nm}$ AlGaN film as the piezoelectric layer.

The frequency responses, $\mathrm{k}_{\mathrm{t}}{ }^{2}, \mathrm{Q}$, and FoM of the SMR device can be analyzed through the network analyzer, which are calculated as follows [1-3]:

$$
\begin{gathered}
\mathrm{k}_{\mathrm{t}}^{2}=\frac{\varnothing}{\tan \varnothing}=\frac{\left(\frac{\pi}{2}\right)\left(\frac{\mathrm{f}_{\mathrm{s}}}{\mathrm{f}_{\mathrm{p}}}\right)}{\tan \left(\left(\frac{\pi}{2}\right)\left(\frac{\mathrm{f}_{\mathrm{s}}}{\mathrm{f}_{\mathrm{p}}}\right)\right)} \cong\left(\frac{\pi}{2}\right)^{2}\left(\frac{\mathrm{f}_{\mathrm{p}}-\mathrm{f}_{\mathrm{s}}}{\mathrm{f}_{\mathrm{p}}}\right) \\
\mathrm{Q}=2 \pi \mathrm{f} \times \tau(\mathrm{f}) \times \frac{\operatorname{mag}\left(s_{11}\right)}{1-\operatorname{mag}\left(s_{11}\right)^{2}} \\
\text { FoM }=\mathrm{Q}_{(\text {device })} \times \mathrm{k}_{\mathrm{t}}{ }^{2} \text { (device) }
\end{gathered}
$$

Among them, $\mathrm{f}_{\mathrm{s}}$ is the series resonance frequency, $\mathrm{f}_{\mathrm{p}}$ is the parallel resonance frequency, $\tau(\mathrm{f})$ is the time delay of the network analyzer, and $\operatorname{mag}\left(s_{11}\right)$ is the return loss $\left(s_{11}\right)$ value. The resulted performance parameters of the SMR device in this work showed that $\mathrm{k}_{\mathrm{t}}{ }^{2}$ was $2.33 \%$, $Q$ value was 96.93 , and FoM was 2.26, respectively. By comparing, the return loss, $\mathrm{k}_{\mathrm{t}}{ }^{2}, \mathrm{Q}$, and FoM values are worse than those obtained in device using the single crystal $\mathrm{AlGaN}$ film as the piezoelectric layer deposited by MOCVD method [19]. The reason may be that the higher the resonance frequency of acoustic wave device, the thinner the piezoelectric layer that is needed, which may result in the poor crystalline characteristics of the piezoelectric layer [8]. The performance of the SMR device can be improved through a thermal annealing process of piezoelectric layer and the precise control of the thicknesses of reflective layers in the Bragg reflector [8].

\section{Conclusions}

In this study, the Bragg reflector, composed of three pairs of $\mathrm{Mo}$ and $\mathrm{SiO}_{2}$ films, was firstly fabricated on a Si substrate, then the AlGaN thin film was successfully deposited on the Bragg reflector by a reactive RF magnetron co-sputtering system at room temperature. Under a sputtering power of $175 \mathrm{~W}$ for $\mathrm{Al}$ target, a sputtering power of $25 \mathrm{~W}$ for $\mathrm{GaN}$ target, a $\mathrm{N}_{2}$ flow ratio of $60 \%$, and a sputtering pressure of $10 \mathrm{mTorr}$, the optimized AlGaN film with a smooth surface, uniform crystal grains, and strong c-axis-orientated crystallization was obtained. The contents of $\mathrm{Al}$ and $\mathrm{Ga}$ in the $\mathrm{AlGaN}$ film were $81 \%$ and $19 \%$, respectively.

The AlGaN-based SMR device with good performance was successfully fabricated. The frequency response $\left(s_{11}\right)$ of the SMR device showed that the resonance frequency was $3.60 \mathrm{GHz}$, the return loss was about $-8.62 \mathrm{~dB}$, the $\mathrm{k}_{\mathrm{t}}^{2}$ was $2.33 \%$, the $\mathrm{Q}$ value was 96.93 , and the FoM value was 2.26 , respectively. 
Author Contributions: Data curation, Y.-C.C. (Yu-Chen Chang); formal analysis, Y.-C.C. (Yu-Chen Chang); writing-original draft preparation, Y.-C.C. (Yu-Chen Chang) and Y.-C.C. (Ying-Chung Chen); writing-review and editing, Y.-C.C. (Ying-Chung Chen) and C.-C.C. All authors have read and agreed to the published version of the manuscript.

Funding: This study was supported by the Ministry of Science and Technology of the Republic of China, Taiwan. (No. MOST 107-2221-E-110-052-MY2, No. MOST 109-2221-E-110-028 and No. MOST 110-2622-E-110-008.) and the Ministry of Education, Taiwan, R.O.C. (107RSI0007).

Institutional Review Board Statement: Not applicable.

Informed Consent Statement: Not applicable.

Data Availability Statement: Not applicable.

Acknowledgments: This study was supported by the Ministry of Science and Technology of the Republic of China, Taiwan and the Ministry of Education, Taiwan, R.O.C.

Conflicts of Interest: The authors declare no conflict of interest.

\section{References}

1. Yu, L.; Jin, H.; Hu, N.; Dong, S.; Luo, J. Flexible film bulk acoustic resonators and filter-like structure made directly on polymer substrates. Integr. Ferroelectr. 2016, 168, 157-162. [CrossRef]

2. Patel, R.; Bansal, D.; Agrawal, V.K.; Rangra, K.; Boolchandani, D. Fabrication and RF characterization of zinc oxide based film bulk acoustic resonator. Superlattices Microstruct. 2018, 118, 104-115. [CrossRef]

3. Corso, C.D.; Dickherber, A.; Hunt, W.D.; Corso, C.D. Lateral field excitation of thickness shear mode waves in a thin film ZnO solidly mounted resonator. J. Appl. Phys. 2007, 101, 054514. [CrossRef]

4. Zhao, J.H.; Xing, Y.H.; Han, J.; Lin, W.K.; Yun, X.F.; Sun, Y.H.; Zhou, X.; Wang, Z.M.; Cao, X.; Zhang, B.S.; et al. The research of dual-mode film bulk acoustic resonator for enhancing temperature sensitivity. Semicond. Sci. Technol. 2021, 36, 025018. [CrossRef]

5. Afzal, A.; Iqbal, N.; Mujahid, A.; Schirhagl, R. Advanced vapor recognition materials for selective and fast responsive surface acoustic wave sensors: A review. Anal. Chim. Acta 2013, 787, 36-49. [CrossRef] [PubMed]

6. Serhane, R.; Abdelli-Messaci, S.; Lafane, S.; Khales, H.; Aouimeur, W.; Hassein-Bey, A.; Boutkedjirt, T. Pulsed laser deposition of piezoelectric $\mathrm{ZnO}$ thin films for bulk acoustic wave devices. Appl. Surf. Sci. 2014, 288, 572-578. [CrossRef]

7. Zhang, X.; Xu, W.C.; Chae, J. Temperature effects on a high Q FBAR in liquid. Sens. Actuator A Phys. 2011, 166, 264-268. [CrossRef]

8. Chang, Y.C.; Chen, Y.C.; Li, B.R.; Shih, W.C.; Lin, J.M.; Chang, W.T.; Cheng, C.C. Effects of Thermal Annealing on the Characteristics of High Frequency FBAR Devices. Coatings 2021, 11, 397. [CrossRef]

9. Kim, H.H.; Ju, B.K.; Lee, Y.H.; Lee, S.H.; Lee, J.K.; Kim, S.W. A noble suspended type thin film resonator (STFR) using the SOI technology. Sens. Actuator A Phys. 2001, 89, 255-258. [CrossRef]

10. Huang, C.L.; Tay, K.W.; Wu, L. Fabrication and performance analysis of film bulk acoustic wave resonators. Mater. Lett. 2005, 59, 1012-1016. [CrossRef]

11. Chung, C.J.; Chen, Y.C.; Cheng, C.C.; Kao, K.S. Synthesis and bulk acoustic wave properties on the dual mode frequency shift of solidly mounted resonators. IEEE Trans. Ultrason. Ferroelectr. Freq. Control 2008, 55, 857-864. [CrossRef] [PubMed]

12. Kim, D.H.; Yim, M.; Chai, D.; Park, J.S.; Yoon, G. Improved resonance characteristics by thermal annealing of $\mathrm{W} / \mathrm{SiO}_{2} \mathrm{multi-layers}$ in film bulk acoustic wave resonator devices. Jpn. J. Appl. Phys. 2004, 43, 1545-1550. [CrossRef]

13. Lee, S.H.; Kim, J.H.; Mansfeld, G.D.; Yoon, K.H.; Lee, J.K. Influence of electrodes and Bragg reflector on the quality of thin film bulk acoustic wave resonators. In Proceedings of the 2002 IEEE International Frequency Control Symposium and PDA Exhibition (Cat. No.02CH37234), New Orleans, LA, USA, 31 May 2002; pp. 45-49.

14. Mirea, T.; Clement, M.; Olivares, J.; Iborra, E. Assessment of the absolute mass attachment to an AlN-based solidly mounted resonator using a single shear mode. IEEE Electron. Device Lett. 2020, 41, 609-612. [CrossRef]

15. Qin, L.F.; Chen, Q.M.; Cheng, H.B.; Wang, Q.M. Analytical study of dual-mode thin film bulk acoustic resonators (FBARs) based on $\mathrm{ZnO}$ and AlN films with tilted c-axis orientation. IEEE Trans. Ultrason. Ferroelectr. Freq. Control 2010, 57, 1840-1853. [PubMed]

16. Sun, P.; Chen, Y.R.; Tang, T.T.; Shen, J.; Liu, X.; Yang, X.M.; Gao, C. Effect of c-axis tilted orientation ZnO thin film on shear-mode bulk acoustic resonator in liquid environment. Mater. Express 2020, 10, 1477-1483. [CrossRef]

17. Chung, C.J.; Chen, Y.C.; Cheng, C.C.; Wei, C.L.; Kao, K.S. Influence of surface roughness of Bragg reflectors on resonance characteristics of solidly-mounted resonators. IEEE Trans. Ultrason. Ferroelectr. Freq. Control 2007, 54, 802-808. [CrossRef] [PubMed]

18. Shealy, J.B.; Hodge, M.D.; Patel, P.; Vetury, R.; Feldman, A.Y.; Gibb, S.R.; Boomgarden, M.D.; Lewis, M.P.; Shealy, J.B.; Shealy, J.R. Single crystal AlGaN bulk acoustic wave resonators on silicon substrates with high electromechanical coupling. In Proceedings of the 2016 IEEE Radio Frequency Integrated Circuits Symposium (RFIC), San Francisco, CA, USA, 22-24 May 2016 ; pp. 103-106.

19. Wang, W.B.; Mayrhofer, P.M.; He, X.L.; Gillinger, M.; Ye, Z.; Wang, X.Z.; Bittner, A.; Schmid, U.; Luo, J.K. High performance AlScN thin film based surface acoustic wave devices with large electromechanical coupling coefficient. Appl. Phys. Lett. 2014, 105, 133502. [CrossRef] 
20. Uehara, M.; Mizuno, T.; Aida, Y.; Yamada, H.; Umeda, K.; Akiyama, M. Increase in the piezoelectric response of scandium-doped gallium nitride thin films sputtered using a metal interlayer for piezo MEMS. Appl. Phys. Lett. 2019, 114, 012902. [CrossRef]

21. Mitterhuber, L.; Hammer, R.; Dengg, T.; Spitaler, J. Thermal Characterization and Modelling of AlGaN-GaN Multilayer Structures for HEMT Applications. Energies 2020, 13, 2363. [CrossRef]

22. Ni, R.X.; Chuo, C.C.; Yang, K.; Ai, Y.J.; Zhang, L.; Cheng, Z.; Liu, Z.; Jia, L.F.; Zhang, Y. AlGaN-based ultraviolet light-emitting diode on high-temperature annealed sputtered AlN template. J. Alloys Compd. 2019, 794, 8-12. [CrossRef]

23. Dinh, D.V.; Amano, H.; Pristovsek, M. Nonpolar m-plane AlxGa1-xN layers grown on m-plane sapphire by MOVPE. J. Cryst. Growth 2019, 512, 100-104. [CrossRef]

24. Othman, N.A.; Nayan, N.; Mustafa, M.K.; Azman, Z.; Hasnan, M.M.I.M.; Bakri, A.S.; Jaffar, S.N.; Bakar, A.S.A.; Mamat, M.H.; Mohd Yusop, Z.M.; et al. Structural and Morphological Properties of AlGaN Thin Films Prepared by Co-sputtering Technique. In Proceedings of the 2021 IEEE Regional Symposium on Micro and Nanoelectronics (RSM), Kuala Lumpur, Malaysia, 2-4 August 2021; pp. 20-23.

25. Chung, C.Y.; Chen, Y.C.; Chen, Y.C.; Kao, K.S.; Chang, Y.C. Fabrication of a 3.5-GHz Solidly Mounted Resonator by Using an AlScN Piezoelectric Thin Film. Coatings 2021, 11, 1151. [CrossRef]

26. Tholander, C.; Abrikosov, I.A.; Hultman, L.; Tasnadi, F. Volume matching condition to establish the enhanced piezoelectricity in ternary $(\mathrm{Sc}, \mathrm{Y})_{0.5}(\mathrm{Al}, \mathrm{Ga}, \mathrm{In})_{0.5} \mathrm{~N}$ alloys. Phys. Rev. B 2013, 87, 094107. [CrossRef] 